\title{
Fases para la Digitalización del Fondo Fotográfico Francisco de Paula Coronado de la Universidad Central "Marta Abreu" de Las Villas
}

\author{
Phases for the Digitization of the Francisco de Paula \\ Coronado Photographic Fund of the Central University \\ "Marta Abreu" of Las Villas
}

\author{
Maritza Beatriz González Hevia \\ maghevia@uclv.cu \\ Universidad Central "Marta Abreu” de Las Villas \\ Alejandro Céspedes Villegas \\ alejandrocv92@nauta.cu \\ Banco Popular de Ahorro Cuba. \\ Asleni Díaz Jiménez \\ adizj@uclv.cu \\ Universidad Central "Marta Abreu” de Las Villas \\ C. Amed Abel Leiva Mederos \\ amed@uclv.edu.cu \\ Universidad Central "Marta Abreu" de Las Villas
}

\section{Resumen}

La digitalización es una de las estrategias más utilizadas para prevenir el deterioro de los fondos documentales. Esta investigación tiene la finalidad de establecer fases para acometer la Digitalización del Fondo Fotográfico Francisco de Paula Coronado de la Universidad Central "Marta Abreu" de Las Villas. Para ello se utilizan métodos tanto del nivel teórico como empírico. Aplicando las técnicas de revisión bibliográfica, entrevista estructurada y cuestionario. Dando como resultado 11 fases que abordan elementos como la Preparación, Digitalización, Reconocimiento de Datos, Indexación, Control de la Calidad, Firma del Documento, Carga de Datos en 
el Archivo Digital, Archivo, Devolución o Expurgo y Preservación Digital. Este resultado responde a la normalización del proceso de digitalización en dicha institución y permitirá, entre otras potencialidades, brindar un servicio de mayor calidad.

\title{
Palabras clave
}

Digitalización; fondo fotográfico; Francisco de Paula Coronado; Universidad Central "Marta Abreu" de Las Villas

\begin{abstract}
Digitization is one of the most used strategies to prevent the deterioration of documentary funds. The purpose of this research is to establish phases to undertake the Digitalization of the Francisco de Paula Coronado Photographic Fund of the Central University "Marta Abreu" of Las Villas. For this, both theoretical and empirical methods are used. Applying the techniques of bibliographic review, structured interview and questionnaire. Resulting in 11 phases that address elements such as Preparation, Digitization, Data Recognition, Indexing, Quality Control, Signature of the Document, Loading of Data in the Digital Archive, Archive, Return or Expurge and Digital Preservation. This result responds to the normalization of the digitalization process in said institution and will allow, among other potentials, to provide a higher quality service.
\end{abstract}

\section{Keywords}

Digitization; Photographic background; Francisco de Paula Coronado; Central University "Marta Abreu" of Las Villas

Recibido: 30/12/2019

Aceptado: $16 / 06 / 2020$

DOI: https://dx.doi.org/10.5557/IIMEI11-N20-031058

Descripción propuesta: González Hevia, María Beatriz; Céspedes Villegas, Alejandro; Díaz Jiménez, Asleni; Leiva Mederos, C. Amed Abel, 2020. Fases para la Digitalización del Fondo Fotográfico Francisco de Paula Coronado de la Universidad Central "Marta Abreu" de Las Villas. Métodos de Información, 11(20), $31-58$ 


\section{Introducción}

La digitalización de fotografías es una alternativa crucial para combatir el deterioro de los soportes tradicionales así como la vía para mejorar la accesibilidad a los fondos fotográficos. Para ello es necesario valorar, de acuerdo con el fondo que se va a digitalizar y el objetivo que se persigue para realizar dicha acción, con cuáles tecnologías se van a trabajar para desarrollar el proyecto de digitalización.

Según las directrices formuladas por la International Federation of Library Associations (IFLA) y el International Council on Archives (ICA) que han fomentado un movimiento hacia la digitalización del acervo bibliográfico de las bibliotecas, y posicionado el tema políticamente para su discusión y prioridad, el proceso de digitalización. "Ha de estar sujeto a una serie de recomendaciones, directrices o pautas que ayuden al profesional a planificar correctamente estos proyectos con el objetivo de optimizar los recursos existentes, lograr la máxima visibilidad de la información digitalizada a través de internet y permitir el intercambio de dicha información y el trabajo cooperativo" (IFLA y ICA 2002).

Uno de los objetivos fundamentales de la digtalización es la conservación del patrimonio fotográfico, siendo la fotografía "un documento que refleja un testimonio visual de acontecimientos políticos, sociales, cíentificos o culturales de la humanidad" (Batista Delgado 2016), una forma de discurso en el que se reflejan los momentos que vive una sociedad y donde se pueden tomar elementos para la reconstrucción de la memoria histórica de un contexto determinado. La fotografía con carácter histórico "servirá para manifestar el progreso de las naciones y por extensión reflejo de la modernidad y desarrollo de las mismas" (Centro de Estudios de Castilla-La Mancha 2018).

La conservación documental "permite la perdurabilidad de las fuentes. La rigurosidad de la conservación permite al documento evitar la restauración, siendo esta la última etapa para salvar el contenido del mismo" (Pérez-Montes Salmerón y Caso Neira 2016).

Es por esto que es importante la necesidad de aplicar una guía de digitalización que establezca unos requisitos concretos necesarios para la 
correcta custodia y preservación de las colecciones fotográficas en la Universidad Central "Marta Abreu" de Las Villas (UCLV). Además se deben implantar "pautas generales adaptables a los disímiles contextos que guíen con criterios básicos el proceso de digitalización de materiales fotográficos para su conservación y preservación a lo largo del tiempo" (Carmenate Torres, Silva y Sanabria 2016).

\section{Materiales y Métodos}

El estudio que se presenta clasifica como no experimental transeccional con alcance descriptivo ya que hace referencia a la caracterización del objeto de estudio en un período determinado. Se utilizan métodos en los niveles teórico y empírico. En el nivel teórico se emplearon el analítico- sintético, inductivodeductivo e histórico- lógico. En el nivel empírico se empleó el análisis documental y la encuesta. La investigación se llevó a cabo mediante las siguientes etapas:

a) Planteamiento del problema: se hizo un primer acercamiento al tema y a las problemáticas que entraña el objeto de estudio. Se comprobó la factibilidad del mismo y se conceptualizaron las guías a seguir para resolver el problema de investigación.

b) Revisión de la literatura: consistió en recopilar toda la información bibliográfica a partir del problema de investigación y los objetivos trazados. Se formula en esta parte de la investigación las cuestiones relativas al alcance del tema y se conforman las estructuras metodológicas que han de servir de base al proceso de investigación.

c) Recolección de los datos: en esta etapa se aplican y conciben los instrumentos de investigación. Se aplicaron una entrevista (Ver Anexo 1) y un cuestionario (Ver Anexo 2) a diferentes profesionales que desempeñan disimiles roles en la institución. Con ello se determinaron las características de la misma y la aptitud para realizar el proceso de digitalización.

d) Análisis de los datos: se utilizaron herramientas para el procesamiento y análisis de los datos, así como tablas y gráficos que ilustran los resultados obtenidos. 
e) Reporte de los resultados: se propuso un procedimiento para la digitalización del fondo de acuerdo a los resultados obtenidos en las etapas anteriores.

Variable escogida: las subcategorías de análisis seleccionadas para la confección del procedimiento se muestran en la Tabla 1.

\begin{tabular}{|c|c|c|}
\hline $\begin{array}{l}\text { Categoría de } \\
\text { Análisis }\end{array}$ & Subcategoría & Ítems \\
\hline \multirow{3}{*}{$\begin{array}{l}\text { Digitalización } \\
\text { de } \\
\text { fondos } \\
\text { fotográficos }\end{array}$} & Normativas & $\begin{array}{l}\text { Utilización de políticas para la } \\
\text { digitalización: } \\
\text { - Política de Selección } \\
\text { - Política de Preservación }\end{array}$ \\
\hline & Tecnologías & $\begin{array}{l}\text { Utilización de tecnologías para la } \\
\text { digitalización: } \\
\text { - Escáner } \\
\text { - Cámara digital } \\
\text { - PC } \\
\text { - Servidor }\end{array}$ \\
\hline & Técnicas & $\begin{array}{l}\text { Utilización de técnicas para la } \\
\text { digitalización: } \\
\text { - Profundidad de bits }\end{array}$ \\
\hline & & $\begin{array}{l}\text { - Píxel } \\
\text { - Formato de archivo } \\
\text { - Compresión } \\
\text { - Resolución } \\
\text { - Calidad de imagen }\end{array}$ \\
\hline & Personal & $\begin{array}{l}\text { Utilización del personal para la } \\
\text { digitalización: } \\
\text { - Capacitación informacional } \\
\text { - Capacitación tecnológica }\end{array}$ \\
\hline & Descripción & $\begin{array}{l}\text { Utilización de la descripción para la } \\
\text { digitalización: } \\
\text { - Metadatos } \\
\text { - Clasificación }\end{array}$ \\
\hline
\end{tabular}




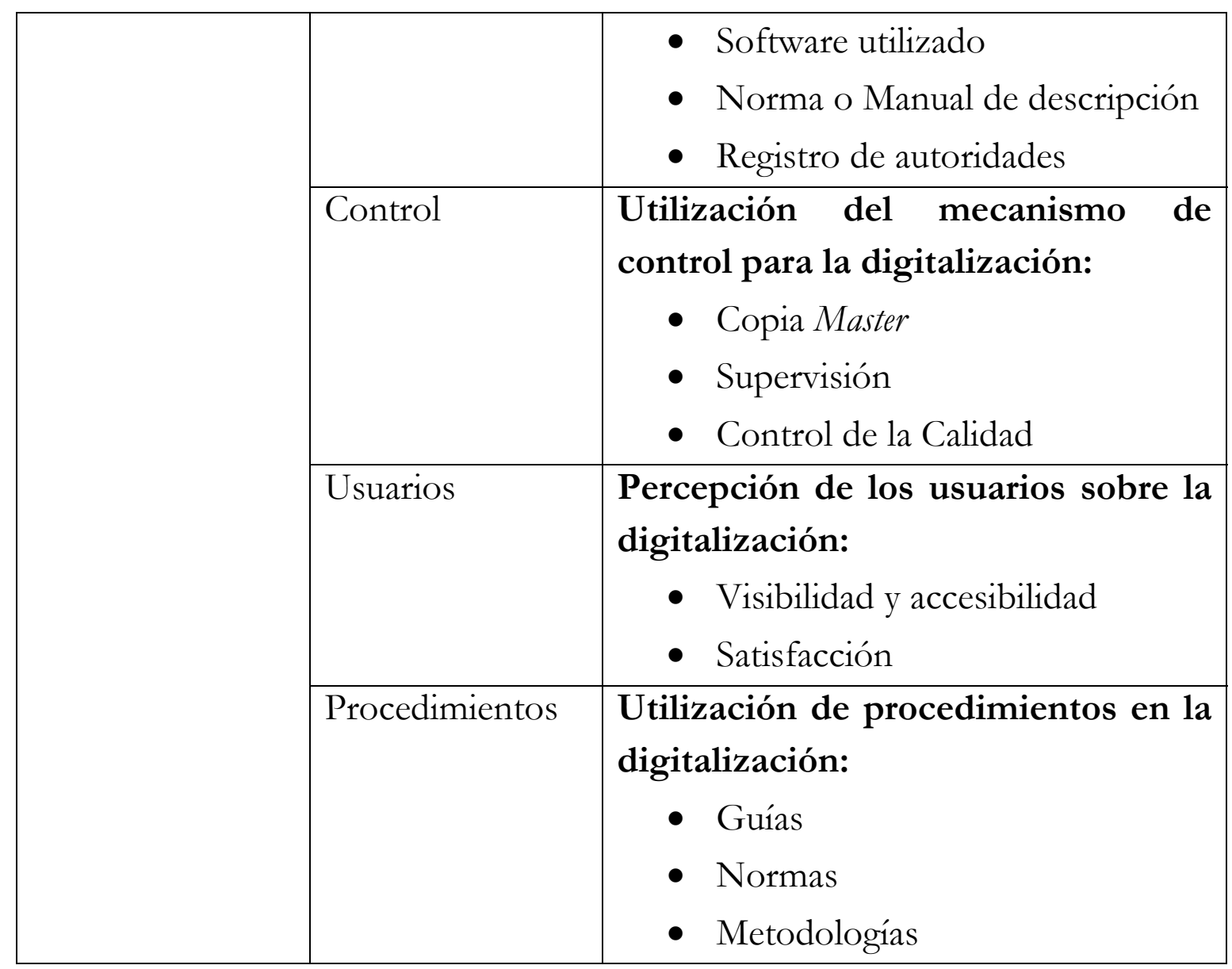

Tabla 1: Variable utilizada en la investigación (Fuente: elaboración propia).

\section{Resultados y Discusión}

En la Universidad Central "Marta Abreu" de Las Villas se encuentra el Fondo Fotográfico Francisco de Paula Coronado, el cual cuenta con 1800 fotografías aproximadamente. En él se muestran imágenes de familias acaudaladas y burguesas, que vivían en Cuba durante la colonia y la neocolonia. Además de imágenes de la Guerra y personalidades de la época.

El procedimiento propuesto se basa en la revisión bibliográfica que se realizó a las diferentes investigaciones relacionadas con los procesos de digitalización. Además, se tienen en cuenta los resultados arrojados en los diferentes instrumentos de recogida de información. El resultado se adaptó a las condiciones tanto del Fondo como al grado de preparación de los especialistas que en él laboran.

\section{Procedimiento de Digitalización}




\subsection{Identificación y Selección}

La primera fase se inicia con la selección de las fotografías y el establecimiento del alcance del proceso de digitalización; copia digitalizada, copia auténtica, tipo de papel, tamaño y tipología documental. Además de determinar cuándo y dónde se va a realizar la digitalización, en base a las necesidades de uso y acceso a los mismos.

Las cuestiones implicadas en la selección de los materiales que se van a digitalizar se examinarán desde dos puntos de vista, según plantea la IFLA:

\section{a) Principales razones para digitalizar}

Para mejorar el acceso: En este caso el interés debe centrarse principalmente en como añadir valor al material original y no en la digitalización como tal. El propósito principal en este caso es posibilitar el uso de los materiales.

- Cuyos originales solo pueden consultarse visitando sus depósitos específicos.

- Que se han deteriorado y necesitan apoyo tecnológico para mostrar su contenido o forma (recuperación de datos).

- De un modo más fácil y productivo que utilizando herramientas avanzadas de ordenador como OCR.

Para la preservación: Si se trata de la conversión digital de materiales que están en peligro o dañados, el objetivo es, en primer lugar, la creación de reproducciones exactas de estos originales en un soporte de larga duración y no la selección de materiales de acuerdo con la demanda. Estas reproducciones deben satisfacer tanto a los usuarios actuales como a los potenciales usuarios del futuro y, por tanto, deben ser de una gran calidad y poseer una gran estabilidad física de modo que puedan mantenerse a lo largo del tiempo.

Un método de selección de materiales originales para su preservación es clasificarlos en tres categorías: 
- Documentos raros, únicos o frágiles, archivos y otros objetos de valor material que necesiten conservarse en su forma original. La conversión digital puede crear copias de gran calidad con un acceso rápido y amplio que en muchos casos protegerá estos materiales de la manipulación.

- Materiales originales con un importante valor intelectual, pero con un valor material relativamente bajo, utilizados intensivamente y dañados o frágiles. Las imágenes digitalizadas son normalmente una buena alternativa para satisfacer las demandas inmediatas. Si los materiales originales están deteriorados, $\mathrm{y}$, por tanto, necesitan ser sustituidos permanentemente.

- Materiales originales muy deteriorados de un alto valor intelectual, pero de un bajo valor material y con un bajo nivel de uso. Este no es un material que interese digitalizar en primer lugar. Si es un material deteriorado que se necesita sustituir por copias que permitan su uso, el microfilm sigue siendo todavía la opción habitual, por ser estable, barata y fácil de almacenar.

\section{b) Criterios de selección}

- Basados en el contenido. Cualquiera que sea el objetivo de la implementación de un proyecto de digitalización, la selección de los materiales originales se basará en mayor o menor medida, en el contenido. Por lo que todo proyecto de digitalización debería tener sus propios principios de valor basados en los objetivos que intenta conseguir.

- Basados en las demandas. El nivel de demanda es de gran interés en el proceso de selección de los materiales para la digitalización. Si el objetivo prioritario es mejorar el acceso, el proceso de selección se regirá por las probabilidades de uso del contenido del material digitalizado. Hay que tener en cuenta una cuestión básica y es, con qué tipo de usuarios quiere interactuar la institución que digitaliza o al menos, a qué usuarios quiere dar prioridad (Departamento de Investigación 2003). 


\subsection{Clasificación y Descripción}

Se deberá clasificar y ordenar las fotografías antes de proceder a su captura, no sólo para garantizar el éxito de la digitalización sino para facilitar las fases posteriores de la misma. Además de identificar si la captura de las fotografías se realizará de forma unitaria, uno a uno, o de forma masiva, por lotes:

a) En el caso de captura unitaria bastará con realizar la ordenación cronológica de las fotografías.

b) En el caso de captura de forma masiva se deberá seleccionar el mecanismo de clasificación y después ordenar cronológicamente las fotografías.

Así mismo se determinará la captura de datos significativos sobre los que se va a realizar el tratamiento informático y corresponderán a los metadatos a incorporar en el archivo digital. Los componentes para tener en cuenta son:

- Datos de contenido (fichero).

- Metadatos mínimos obligatorios de la imagen electrónica de acuerdo a las necesidades de cada institución.

- Firma o controles de seguridad que garanticen la integridad de la fotografía.

- Metadatos relacionados con el proceso de digitalización (características técnicas de la captura).

Algunos de los estándares descriptivos más difundidas que establecen cuáles son los datos que deben señalarse son:

a) AACR2 (Normas Angloamericanas de Catalogación 2* Edición): fijan pautas para la descripción catalográfica de documentos bibliográficos y multimediales.

b) Dublin Core: para promover tipos homogéneos de metadatos para describir los documentos digitales, incluidos las imágenes.

c) ISAD (G) (General International Standard Archival Description): guía que ayuda a asegurar descripciones coherentes, facilitar la recuperación y el 
intercambio de información, compartir encabezamientos autorizados e integrar descripciones en un sistema unificado de información. A pesar de que es aplicable a todo tipo de documentos, su importancia reside en la capacidad para describir el contexto y el contenido del documento. Fue elaborada en 1993 por el Comité de Normas de Descripción del ICA.

d) ISAAR (CPF) (International Standard Archival Authority Record for Corporate Bodies, Persons and Families): destinada a la descripción de puntos de acceso sobre los productores de documentos (entidades, personas y familias).

e) EAD (Encoded Archival Description): es una norma que utiliza un vocabulario XML (Extensible Markup Language) para la codificación de instrumentos de descripción de archivos con el fin de publicar, intercambiar y usar la información archivística a través de internet.

f) PREMIS (PREservation Metadata Implementation Strategies): es un modelo de datos común para organizar los datos que se originan y resultan de la preservación.

\subsection{Preparación}

En esta etapa se preparan las fotografías a capturar, revisándolas una a una. Deshaciéndose de cualquier elemento que impida la ágil captura de las mismas o que puedan entorpecer o imposibilitar el proceso de digitalización. La preparación de las fotografías es la primera etapa del proceso de digitalización y tiene como objetivo:

- Captar una imagen clara y fiel.

- Agilizar el proceso.

- Evitar el deterioro de las fotografías que se encuentran en mal estado.

La preparación implica el cumplimiento de los siguientes pasos:

a) Depuración: Retirar y eliminar los duplicados, así como documentos de apoyo no útiles.

b) Limpieza: Tiene como propósito eliminar la suciedad acumulada que dificulta la lectura de las fotografías. Retirar ganchos, clips y todos los objetos metálicos. Si se trata de tomos es necesario retirar los empastes. 
c) Corrección del plano: Las fotografías no deben presentar dobleces, pliegues u otra clase de distorsiones que puedan entorpecer el proceso de digitalización.

d) Unión de rasgaduras, roturas y cortes: Las rasgaduras, roturas y cortes son deterioros que afectan la estructura del soporte. Estos deterioros son generalmente ocasionados por la incorrecta manipulación, almacenamiento o sistemas de agrupación como ganchos de cosedora o ganchos legadores inadecuados.

e) Foliación: Foliar las fotografías, se recomienda que este proceder se realice cronológicamente, continuando con las relaciones establecidas por el orden de creación entre una y otra.

f) Conservación: Llevar un control estricto de las fotografías que se van digitalizando y guardar los originales.

\subsection{Digitalización o Reprografía}

En esta etapa se obtiene la imagen digital de la fotografía original en soporte papel. Se conseguirá como resultado un fichero con una imagen en la memoria del sistema al que está asociado el dispositivo (escáner o cámara digital).

Esta imagen debe representar fielmente al original en cuanto a la apariencia, forma y contenido, minimizando las variaciones que se puedan presentar. Una vez digitalizada la fotografía se puede optimizar la imagen electrónica, siendo este proceso un elemento fundamental para lograr un resultado lo mejor posible. El uso adecuado de este proceder no incide en la autenticidad de la imagen digitalizada. Esta optimización comprende aspectos tales como: reorientación, eliminación de bordes negros u otros relacionados con la imagen del documento en físico original, siempre respetando la geometría en tamaño y proporción.

Las acciones a realizar en esta etapa son:

a) Definir el formato del fichero que contiene la fotografía digitalizada. Para la carga de una imagen al Archivo Digital es recomendable que el formato final del mismo sea un PDF (Portable Document Format), con una o varias 
páginas, cuando el destino es la consulta. O formato TIFF cuando el destino es la preservación digital de la fotografía.

b) Establecer los parámetros de digitalización (resolución, profundidad de bits, etc.)

c) Garantizar el equilibrio entre una calidad visual aceptable para el usuario y el tamaño del fichero.

d) Decidir si se va a crear un único archivo, con una o varias páginas, por cada fotografía original o varios archivos, una por cada página, según decida la Política de Preservación Digital de la institución.

e) Las especificaciones técnicas evolucionan rápidamente por lo que cada institución deberá asegurar la legalidad o utilidad de la imagen digitalizada con una adecuada selección del sistema.

f) El acceso a la información supone que está permanecerá legible, inteligible y recuperable:

- Legible: es poder acceder en todo momento presente y futuro a la información sin pérdida de datos, por esta razón hay que garantizar las condiciones de almacenamiento y de lectura.

- Inteligibilidad: la información producida y recuperada por un sistema de digitalización permanece comprensible para otro sistema.

- Recuperación: implica el aseguramiento de encontrar la información almacenada y el acceder a ella fácilmente. Para garantizar el acceso a la información se debe tener en cuenta:

a. Establecer una estrategia de migración que permita la evolución del equipo, los programas informáticos y los soportes de almacenamientos de datos al ritmo de los cambios tecnológicos.

b. Etiquetas de encabezamiento estandarizadas que puedan ser leídas por otros sistemas.

c. Definición detallada de la estructura de etiquetas y lenguaje fuente.

g) La verificación de la calidad de las imágenes se deberá realizar mediante la toma de imágenes, su mejoramiento, compresión y descomposición.

h) La funcionalidad del sistema depende principalmente de su arquitectura y compatibilidad y se deberá tener en cuenta la protección de la información 
digitalizada, el control de acceso, la evolución de las tecnologías y las auditorías. Todo ello dispuesto en la Política de Preservación Digital de la institución.

\subsection{Reconocimiento de datos}

Está relacionado con la de digitalización y en muchos casos se realiza simultáneamente. El objetivo del mismo es la extracción de la información relevante contenida en la propia fotografía, con el fin de facilitar su tratamiento posterior. Esta información constituirá algunos de los metadatos a incorporar al archivo digital y se realizan las siguientes tareas:

Seleccionar el tipo de reconocimiento que va a llevarse a cabo:

- El primer tipo de reconocimiento es el manual. Una vez digitalizada la fotografía se teclean los datos significativos que identifican la imagen en la aplicación de gestión correspondiente.

- Reconocimiento automático. Se hará uso de técnicas para la extracción automatizada de los datos significativos de la fotografía. Existen diferentes técnicas para llevar a cabo un reconocimiento automático:

a. Utilización de OCR (Reconocimiento Óptico de Caracteres): Reconoce caracteres que se encuentran en una imagen, con el beneficio que el texto puede interactuar con programas de edición de texto o de búsquedas, etc.

b. Utilización de ICR (Reconocimiento Inteligente de Caracteres): reconoce textos mecanografiados o con caracteres latinos, el ICR lo hace con texto escrito a mano alzada. Estas herramientas son de gran valor en el empleo de reconocimiento de textos en imágenes de libros antiguos y valiosos.

c. Reconocimiento de código de barras asociado al documento. En el caso de que se hayan generado hojas identificativas durante la fase de clasificación, con el objeto de clasificar la documentación, se procederá al reconocimiento de los datos identificativos contenidos en las mismas. 


\subsection{Indexación}

Se reúne toda la información identificativa de las fotografías, muy relacionada con la etapa de clasificación y con el resultado obtenido en la fase de reconocimiento de datos. En esta etapa se debe obtener toda la información necesaria para la carga de la documentación en el archivo digital. Toda esta información es necesaria y relevante para la identificación de las fotografías y sus futuras consultas.

Las tareas a realizar en la etapa de indexación son:

a) Reunir la información identificativa de las fotografías, en el caso de que no se hayan obtenido todos estos datos de forma automática en la etapa de reconocimiento de datos, se deberá disponer de una interfaz para que se puedan introducir manualmente. Si por el contrario se obtuvieron de forma automática, no será necesaria ninguna intervención manual.

b) Se debe asegurar que se ha generado una única imagen a almacenar en el archivo digital por cada documento original, ya sea de una o varias páginas.

c) Garantizar que el formato del fichero que contiene la imagen digital es PDF para su posterior consulta.

\subsection{Control de calidad}

Consiste en verificar que tanto la imagen digital como los datos significativos obtenidos en el proceso de digitalización son fieles a la fotografía original en papel y cumplen con unos requisitos mínimos de calidad. El mismo abarca procedimientos y técnicas para verificar la calidad, precisión y consistencia de los productos digitales. Si durante esta etapa se determinara que la digitalización no ha sido correcta, por ejemplo, que la imagen no es legible o no presenta la calidad mínima suficiente, se realizará una nueva captura. 
Por esta razón el proceso de digitalización debe ser acompañado de un plan de seguimiento rutinario que permita garantizar la óptima digitalización en cada una de sus etapas. Las tareas más significativas a realizar son:

a) Establecer un programa de control de calidad, donde se definan en detalle todos los pasos para la comprobación de que la digitalización es correcta, así como los requisitos mínimos que deben cumplir las imágenes digitalizadas.

b) Determinar si se inspeccionarán todas las imágenes, o solamente un subconjunto de prueba, de forma manual o visual, de forma automática con software re específico y para ello, comprobaciones de páginas en blanco y páginas muy oscuras en base al tamaño de la imagen o de forma mixta, primer filtro de forma automática y un segundo filtro de forma visual.

c) Indicar las condiciones por las que se determina realizar una nueva digitalización de las fotografías.

d) Realizar un seguimiento de forma exhaustiva al proceso de digitalización, en el que deberán generarse informes de seguimiento de incidencias y estadísticas de digitalización. En ellos se indicarán aspectos como número de fotografías digitalizadas y número de imágenes con incidencias.

\subsection{Firma de documento}

Se plantea con el fin de dar una validez legal al proceso de digitalización y de cumplir con la normativa existente en temas como la creación de copias auténticas de fotografías originales en papel. Puede aparecer la necesidad de firmar las imágenes resultantes de la digitalización, pero el proceso es opcional.

La tarea a realizar requiere decidir si las fotografías van a firmarse, si se va a llevar a cabo con una firma de servidor, software o con una firma cliente. Lo más habitual es que en caso de contar con un número reducido de documentos digitalizados se haga uso de la firma de cliente. En caso de contar con un número elevado de fotografías digitalizadas se haga uso de la firma de servidor. 


\subsection{Carga de datos en el archivo digital}

Una vez que se dispone de todos los metadatos necesarios para cargar el documento con los datos reunidos en la etapa de indexación y el propio fichero que contiene la imagen digital del mismo. Se procede a la carga de datos en el archivo digital, teniendo en cuenta que, en el caso de realizar todo el proceso completo de digitalización para cada imagen, la carga en el archivo digital será realizada por la aplicación integrada con el software de captura.

Dicha aplicación se comunicará con el archivo digital, haciendo uso de Framework de Servicios Documentales (FSD). Si por el contrario la captura es masiva, será el software de digitalización el que se encuentre integrado con el archivo digital para realizar directamente su almacenamiento.

Así mismo, si se llega a esta etapa con un conjunto de imágenes digitalizadas, sin que el software de captura se encuentre integrado con el archivo digital. A continuación, se deberá generar igualmente la estructura adecuada para su almacenamiento masivo. En todos estos casos se hará uso del proceso de carga masiva que proporciona el archivo digital para el almacenamiento de un lote de imágenes.

\subsection{Archivo, Devolución o Expurgo}

Terminado el tratamiento de digitalización y la carga en el archivo digital se llega a la etapa final del proceso de digitalización. La documentación en papel tiene que ser archivada, devuelta o expurgada, según corresponda en cada caso. Para ello se auxilia el personal de la comisión de valoración documental creada previamente y que será la responsable de la creación de la Tabla de Retención Documental, y por ende del destino de las fotografías y la gestión de los documentos originales en papel tras la finalización del proceso de digitalización. Es muy importante desarrollar este propósito con suma cautela, debido a que no existe una normativa relacionada con la temática en Cuba.

\subsection{Preservación digital}


La preservación digital supone la selección y puesta en práctica de un conjunto de estrategias con el objetivo de lograr la preservación a largo plazo de las fotografías patrimoniales. Incluso de facilitar la recuperación de los contenidos almacenados en los archivos digitales. Debido a los rápidos avances tecnológicos, al crecimiento de la información y la diversidad de formatos instituciones como la IFLA, el ICA en el 2002 y la Oficina de la UNESCO en Quito el 2015 se han pronunciado sobre la necesidad de establecer estrategias para la preservación digital, dichas estrategias abarcan:

a) Preservación de la tecnología: Consiste en preservar el ambiente tecnológico para visualizar y editar el contenido digital, incluyendo software y hardware, como, por ejemplo: sistemas operativos, programas de visualización, periféricos de lectura y escritura de medios de almacenamiento secundario.

b) Migración: Se refiere a superar la obsolescencia tecnológica al transferir o adaptar el contenido digital de una generación de hardware y software hacia otra generación. Tiene la desventaja de ocasionar pérdidas en la información tras migraciones sucesivas.

c) Reformateo: Se refiere a cambiar el contenido digital de un formato a otro.

d) Rejuvenecimiento: Se refiere a copiar el contenido digital de medio de almacenamiento a otro nuevo del mismo tipo. O bien, escribir cada determinado tiempo el contenido digital a un medio nuevo para evitar que el contenido se pierda a causa de la degradación natural del medio por el transcurso del tiempo.

e) Emulación: Permite que el software original sea usado sin necesidad de que el sistema original que lo ejecutaba siga existiendo. La emulación obliga a preservar una cantidad importante de información.

f) Replicación: Se refiere al hecho de mantener una o más copias de un mismo contenido digital.

g) Estandarización: Se refiere al hecho de utilizar algún formato estándar para la representación del material digital. Esto garantiza un mejor soporte de herramientas para administrar el material digital, una mayor duración del formato y una mejor migración ante los cambios tecnológicos.

h) Encapsulado: refiere a empaquetar la información que se desea preservar junto con los metadatos descriptivos y mantenerlos en una 
única localización. Además de la emulación existen los otros factores clave para la preservación de duración larga:

- Auto documentación: capacidad de entender y decodificar la información preservada sin hacer referencia a documentación externa.

- Auto suficiencia: minimización de dependencias con respeto a sistemas, datos o documentación.

- Documentación de contenido: habilidad para que un usuario futuro encuentre o implante el software para visualizar la información preservada.

- Reservación de organización: habilidad para almacenar la información que le permita a la organización el uso eficiente de la información preservada.

i) Autenticidad: Se refiere al hecho de asegurar la integridad de la información digital. Existen muchas causas por las cuales se puede corromper la información digital: virus, negligencias, fallas de los medios de almacenamiento, ataques informáticos maliciosos, etc. Para asegurar la autenticidad se propone utilizar firmas digitales sobre la información digital.

j) Arqueología digital: Es el proceso de recuperar la información a partir de medios de almacenamiento digital dañados o antiguos.

k) Cuidado duradero: El cuidado duradero debe ser visto como una estrategia continúa para asegurar que las fotografías digitales se encuentren en óptimas condiciones. En el cuidado de una colección, los archivos deben almacenarse en medios y ubicaciones no sólo seguros, sino también confiables. Además, deben manipularse con base en las pautas de aceptación internacional, orientadas a optimizar su expectativa y la calidad de duración.

\section{Conclusiones}

- La digitalización de documentos fotográficos patrimoniales es un proceso que permite la utilización de la información en otros formatos y mitiga el 
deterioro que presentan los soportes tradicionales, constituye una solución muy viable para la salvaguarda de los fondos institucionales.

- El proceso de digitalización en la Dirección de Información Científico Técnica de la Universidad Central "Marta Abreu" de Las Villas presenta debilidades que atentan contra la calidad del mismo, destacando factores como la poca preparación informacional de los especialistas y la ausencia de equipamiento tecnológico.

- El procedimiento expuesto establece un conjunto de elementos básicos que permiten normalizar las acciones del proceso de digitalización. Presenta etapas básicas y comunes a otros procedimientos consultados como son: Identificación y Selección del material a digitalizar, además de la Clasificación y Descripción. Cuenta también con las etapas de Preparación; Digitalización o reprografía; Reconocimiento de datos; Indexación; Control de calidad; Firma del documento; Carga de datos en el archivo digital; Archivo, Devolución o Expurgo.

- La herramienta cuenta también con etapas que son novedosas como la Preservación Digital. La misma consiste en estrategias para lograr la conservación a largo plazo de la información digitalizada. Proponiendo para ello métodos que pueden ser utilizados conjunta o indistintamente.

\section{Bibliografía}

32 CONFERENCIA GENERAL DE LA UNESCO, 2003. Proyecto de Carta para la Preservación del Patrimonio Digital. En: UNESCO [en línea]. Disponible en: $\quad \underline{h t t p: / / u n e s d o c . u n e s c o . o r g / a r k: / 48223 / p f 0000133171 ~ s p a . p a g e ~}=85$ [consulta: 20 septiembre 2019]

ADMINISTRACIÓN PÚBLICA NACIONAL DE ARGENTINA, 2014. Manual de Digitalización de Documentos de la Administración Pública Nacional. [en línea]. Disponible en: http://ogpargentina.files.wordpress.com/2015/03/anexo-ii-informeautoevaluacic3b3n-manual-de-digitalizacion-borrador.pdf [consulta: 15 septiembre 2019]

ARCHIVO GENERAL DE LA NACIÓN DE COLOMBIA, 2014. Preservación digital a largo plazo. [en línea]. Disponible en: www.archivogeneral.gov.co > Infografias > 13 PreservacionLargoPlazo [consulta: 1 octubre 2019]

BATISTA DELGADO, Adiela Neyda, 2016. La gestión del patrimonio fotográfico en la Universidad de La Habana [en linea]. Tesis doctoral. Universidad de Granada [consulta: 3 noviembre 2018]. Disponible en: https://hera.ugr.es/tesisugr/26349620.pdf 
BERMÚDEZ MUÑOZ, María Teresa, 2017. Guía para digitalizar documentos [en línea] [Consultado el 13 de noviembre de 2018]. Disponible en: http://uis.edu.co/intranet/calidad/documentos/gestion documental/GUIAS LGGD.11.pdf [consulta: 13 noviembre 2019]

BLAYA, Fernando, et al, 2016. Aplicación de la digitalización para el estudio, conservación y explotación turística del patrimonio: un caso práctico de un conjunto de bodegas subterráneas - declaradas Bien de Interés Cultural (BIC). Arte, Individuo y Sociedad [en línea]. Madrid: Ediciones Complutense, vol.1, no. 29, pp. 167-180 [consulta: 2 abril 2020]. ISSN 1131-5598. Disponible en: http://revistas.ucm.es/index.php/ARIS/article/download

CAPOTE MERCADAL, Laura, 2017. Un modelo de descripción para el Fondo Fotográfico Benjamín Rodríguez Delfín. Ciencias de la Información [en línea]. La Habana: Instituto de Información Científica y Tecnológica, vol.48, no.1, pp. 27-36 [consulta: 5 enero 2019]. ISSN 0864-4659. Disponible en: www.cinfo.idict.cu/index.php/cinfo/article/view/811/art\%204

CARMENATE TORRES, Yissel Noemys, SILVA, Niliek y SANABRIA, Liliet, 2016. Pautas de digitalización de fotografía para medios de prensa impreso en Cuba. En: Congreso Internacional de Información (INFO) [en línea]. [consulta: 20 enero 2019]. Disponible en: www.congresoinfo.cu/index.php/info/2016/paper/viewFile/166/66

CENTRO DE ESTUDIOS DE CASTILLA-LA MANCHA, 2018. Fotografía y patrimonio cultural [en línea]. Cuenca: Ediciones de la Universidad de Castilla-La Mancha y Centro de Estudios de Castilla-La Mancha [consulta: 10 noviembre 2019]. ISBN 978-84-9044-333-0. Disponible en: http://unizar.es/artigrama/pdf/27/2monografico/02.pdf

CRUZ MUNDET, José Ramón, 2015. Estrategias de preservación digital permanente en los archivos nacionales: un estudio comparativo. Boletín $A N A B A D$ [en línea]. Madrid: Dialnet, vol. LXV, no. 3, pp. 127-148 [consulta: 21 septiembre 2018]. Disponible en: www.dialnet.unirioja.es

CUMBE MORÁN, Vicente Mauricio, 2018. Metodología para proceso de digitalización de documentos y desarrollo de aplicativo web para el control de trabajo diario de personal de digitalizado para la empresa Truebusiness [en línea]. Proyecto fin de carrera. Universidad de Guayaquil [consulta: 1 enero 2019]. Disponible en: http://repositorio.ug.edu.ec/handle/redug/28768

DEPARTAMENTO DE INVESTIGACIÓN, 2003. Tutorial de digitalización de imágenes: Llevando la Teoría a la Práctica. En: Biblioteca de la Universidad de Cornell [en línea] Disponible en: http://preservationtutorial.library.cornell.edu/tutorialspanish/tutorial Spanish.pdf [consulta: 3 noviembre 2019]

DEPARTAMENTO DEL META, 2015. Manual de digitalización. En: Secretaría Administrativa [en línea]. Disponible en: www.meta.gov.co > files > M-RF-01 MANUAL DIGITALIZACION V1 [consulta: 18 febrero 2019]

FUENTES DE CÍA, Ángel María y ROBLEDANO ARRILLO, Jesús, 2014. Tema 3: La identificación y preservación de los materiales fotográficos. En: Manual de 
documentación fotográfica [en línea]. [consulta: el 8 de febrero de 2019]. Disponible en: http://ocw.uc3m.es/biblioteconomia-y-documentacion/documentacionaudiovisual/temas-teoria/DA OCW Tema3 2014.pdf

GARCÍA, Efraín y OSUNA, Rubén, 2017. Fundamentos de fotografía digital. En: INNOVA [en línea]. Disponible en: http://ocw.innova.uned.es/ocwuniversia/tecnologiaelectronica/fundamentos-de-fotografiadigital/pdf/fundamentos.imagen.digital4.pdf [consulta: 13 diciembre 2019].

GIMÉNEZ CHORNET, Vicent, 2014. Criterios ISO para la preservación digital de las fotografías de archivo. Códices [en línea]. vol.10, no. 2, pp. 135-150 [consulta: 13 octubre 2019]. ISSN 1794-9815. Disponilbe en: http://vicentgimenez.net/Criterios-ISO.pdf

GÓMEZ MIELES, Juan Manuel y ZAMBRANO MURILLO, Ángel Alexander, 2016. Proyecto de Digitalización Para la Colección Documental Patrimonial del Archivo Histórico de la Universidad Técnica de Manabí. Journal of Computer Science and Information Tecbnology [en línea]. vol. 4, no. 1, pp. 25-38 [consulta: 10 enero 2019]. ISSN: 2334-2366. Disponible en: http://jcsitnet.com/journals/jcsit/Vol 4 No 1 June 2016/2.pdf

HERNÁNDEZ CONTRERAS, Nancy, BATISTA DELGADO, Adiela Neyda y DELGADO VARONA, Aleida Ofelia, 2016. Propuesta de un modelo de gestión para el patrimonio fotográfico en las universidades cubanas: una experiencia en la Universidad de Ciencias Médicas de La Habana. Revista Cubana de Información en Ciencias de la Salud [en línea]. La Habana, vol. 4, no. 27, pp. 474-490. [consulta: 15 marzo 2019]. ISSN 2307-2113. Disponible en: http://scielo.sld.cu/scielo.php

HURTADO CAMPUZANO, Alex Alain, 2018. Herramienta informática para la digitalización de archivos y patrimonio documental. En: Congreso Internacional de Información (INFO) [en línea]. [consulta: 21 marzo 2019]. Disponible en: http://www.congreso-info.cu/index.php/info/info2018/paper/view

INTERNATIONAL FEDERATION OF LIBRARY ASSOCIATIONS AND INSTITUTIONS (IFLA) y INTERNATIONAL COUNCIL ON ARCHIVES (ICA), 2012. Directrices para proyectos de digitalización de colecciones y fondos de dominio público, en particular para aquellos custodiados en bibliotecas y archivos [en línea]. España: Ministerio de Cultura [consulta: 20 enero 2019]. ISBN 848181-271-4. Disponible en: https://www.ifla.org/files/assets/preservationand-conservation/publications/digitization-projects-guidelines-es.pdf

KODAK ALARIS, 2017. Focusing more on the forest, and less on the trees. Why total system image quality is more important than any single component of your next document scanner. En: CIS [en línea]. Disponible en: www.kodakalaris.com [consulta: 8 diciembre 2019]

OFICINA UNESCO QUITO, 2015. Patrimonio Documental según la UNESCO. En: UNESCO [en línea]. Disponible en: http://www.unesco.org/new/fileadmin/MULTIMEDIA/FIELD/Quito/pdf 
/Patrimonio Documental conforme UNESCO.pdf [consulta: 10 octubre 2019]

PAZ ENRIQUE, Luis Ernesto, et al., 2019. Fondos documentales del Archivo Parroquial de la Iglesia Católica "San Pedro y San Pablo" de Corralillo. Bibliotecas Anales de Investigación [en línea]. vol. 12, no. 1, pp. 41-51 [consulta: 28 febrero 2019]. ISSN 0006-176X. Disponible en: https://www.researchgate.net/publication/307928018 Fondos documentales del Archivo Parroquial de la Iglesia Catolica San Pedro y San Pablo d $\underline{\text { e Corralillo }}$

PÉREZ-MONTES SALMERÓN, Carmen María y CASO NEIRA, Mar, 2016. La importancia de un patrimonio documental: los archivos científicos. En: CSIC [en línea]. Disponible en: https://digital.csic.es/bitstream/10261/2957/1/archivoscientificos.pdf [consulta:10 noviembre 2018]

ROBLEDANO ARRILLO, Jesús, 2011. Mejora del rango dinámico en la digitalización de documentos desde una perspectiva patrimonial: evaluación de métodos de alto rango dinámico (HDR) basados en exposiciones múltiples. Revista Española de Documentación Cientifica [en línea]. vol. 3, no. 34, pp. 357-384 [consulta: 5 mayo 2019]. ISSN 0210-0614. Disponible en: https://www.researchgate.net/publication/47540993 Mejora del rango dina mico en la digitalizacion de documentos desde una perspectiva patrimoni al evaluacion de metodos de alto rango dinamico HDR basados en exp osiciones multiples

WILLIAMS MAP, Elvia Leticia, 2012. Propuesta para la digitalización del Fondo Documental del Dr. Belisario Porras [en linea]. Trabajo fin de master. Universidad Internacional de Andalucía [consulta: 18 diciembre 2018]. Disponible en: http://hdl.handle.net/10334/1789 


\section{Anexo 1}

\section{Guía de entrevista}

Nombre del entrevistado:

Profesión del entrevistado:

Labor que desempeña:

Departamento al que pertenece:

$>$ Experiencia en la labor que ocupa:

$>$ Funciones que realiza:

\section{Datos relacionados con la estructura administrativa que posee la institución}

$>$ ¿Cuál es la estructura de la institución?

$>$ ¿Existe algún departamento encargado de realizar el proceso de digitalización?

¿Quiénes son los ejecutores del proceso de digitalización?

\section{Datos sobre el proceso de digitalización}

$>$ ¿Tienen conocimiento sobre que es un proceso de digitalización?

$>$ ¿Conoce qué implicaciones tiene el proceso?

$>$ ¿Existe alguna política de selección del material a digitalizar?

$>$ ¿Se emplea algún procedimiento para realizar el proceso de digitalización?

$>$ ¿Tiene conocimiento de que exista alguna política para la preservación de las fotografías digitalizados?

¿Conoce las etapas o pasos del proceso de digitalización que realiza su institución?

¿Existe en la institución personal capacitado para realizar el proceso de digitalización? 


\section{Anexo 2}

Estimado especialista; el presente cuestionario es parte de una investigación de pregrado de la carrera Licenciatura en Ciencias de la Información. Su objetivo es conocer cuál es el estado de los procesos de digitalización en el Fondo Fotográfico Francisco de Paula Coronado de la Universidad Central "Marta Abreu" de Las Villas.

Su colaboración es de suma importancia para someter a consideración elementos del entorno que se investiga. La información que usted proporcione será utilizada con la más estricta confidencialidad y para uso exclusivo de dicha investigación.

\section{Muchas gracias}

Fecha:

Profesión del entrevistado :

Labor que desempeña:

Departamento al que pertenece:

Experiencia en la labor que ocupa:

Funciones que realiza:

1. ¿En su institución existe alguna política o estándar que regule la selección de las fotografías que se digitalizarán? Sí / No

2. ¿Existe algún departamento encargado de realizar el proceso de digitalización? Sí / No

3. ¿Por qué realizar el proceso de digitalización?

Valor Patrimonial:

Gran Impacto:

Alta Demanda:

Otros:

4. ¿Con qué equipamiento tecnológico dispone la institución?

PC: Sí / No

Escáner Plano (de mesa): Sí / No 
Escáner de Tambor: Sí / No

Escáner para Transparencias: Sí / No

Escáner de Microfilms: Sí / No

Escáner de Mano o Portátil: Sí / No

Cámara Digital: Sí / No . De ser positiva su respuesta. Especifique:

Compacta Reflex

Otros:

5. ¿Cuenta con personal capacitado encargado de llevar a cabo los procesos de digitalización? Sí / No

Capacitación Tecnológica _ _ Informacional Ambas

6. ¿Se realiza la preparación adecuada de la información a digitalizar? Sí No En Ocasiones

7. ¿En caso de ser realizada la preparación es llevada a cabo por especialistas? Sí No En Ocasiones

8. ¿Cuáles son los formatos o estándares, que emplea para la digitalización? PDF JPEG TIFF Otro

9. ¿Usa múltiples formatos para almacenar la información?

Sí No En Ocasiones

10. ¿Realiza copias de respaldo del archivo master? Sí No En Ocasiones

11. ¿Qué nivel de resolución utiliza en las imágenes electrónicas? 200 Puntos por cada pulgada como mínimo 300 Puntos por cada pulgada 400 Puntos por cada pulgada 1200 Puntos por cada pulgada 
2400 Puntos por cada pulgada

Otras

12. ¿Qué tamaño suelen tener las fotografías que digitaliza?

De 100 a 200 Kilobytes

De 200 a 300 Kilobytes

De 300 a 400 Kilobytes

De 400 a 500 Kilobytes

De 500 a 600 Kilobytes

De 600 a 700 Kilobytes

De 700 a 800 Kilobytes

De 800 a 900 Kilobytes

De 1 a 2 Megabytes

Otros

13. ¿Qué nivel de profundidad de bits o resolución cromática utiliza en las imágenes electrónicas?

8 Bits a cada Píxel 24 Bits a cada Píxel Otras

14. ¿Se realiza la extracción de metadatos de la información digitalizada? $\mathrm{Si}$ No En ocasiones

15. ¿Determina un vocabulario normalizado para extraer metadatos?

Si

Nómbrelo

No En ocasiones

16. ¿Qué metadatos extrae de la información digitalizada?

Nombre de la colección por temática

Título de la información

Fecha de transformación de la información

Fecha de surgimiento de la fotografía original

Descripción bibliográfica 
Indicador para el acceso a la versión master u original

Idioma

Marca de agua

Forma de ingreso

Soporte

Peso de la información

Descriptores de materia

País

Notas de interés

Otro

17. ¿La clasificación de las fotografías digitalizadas se realiza de forma manual? $\mathrm{Si}$ No En ocasiones

18. ¿La institución exige que las fotografías digitalizadas contengan marca de agua?

Si No En ocasiones

19. ¿La institución tiene implementada alguna herramienta para supervisar las etapas del proceso de digitalización?

Sí No

20. ¿La institución realiza algún control de calidad de los medios tecnológicos para la digitalización?

Sí No En ocasiones

21. ¿La institución emite un informe de incidencias del proceso? Sí No

22. ¿La institución elabora y analiza informes de nivel de satisfacción de usuarios?

Sí No En ocasiones 
23. ¿La institución cuenta con algún encargado de la supervisión de la calidad de los archivos de copia y acceso?

Si Técnico Especialista

Otros

No

24. ¿Su institución cuenta con algún plan para la identificación y control de riesgo y vulnerabilidades de los volúmenes digitalizados?

Sí No

25. ¿La información digitalizada se encuentra visible y accesible para los usuarios?

Si __ Biblioteca Digital Repositorio

Base de Datos Carpetas en PC Otros

No En proceso

26. ¿La institución planifica el destino de las fotografías empleados en la digitalización?

$\mathrm{Si}$ No En ocasiones 